\title{
Oil Price, Overleveraging and Shakeout in the Shale Energy Sector: Game Changers in the Ofl Industry
}

\section{Arkady Gevorkyan and Willi Semmler}

\author{
Schwartz Center for Economic Policy Analysis (SCEPA) \\ Department of Economics \\ The New School for Social Research \\ 6 East 16th Street, New York, NY 10003 \\ economicpolicyresearch.org
}

Suggested Citation: Gevorkyan, A. and Semmler, W. (2015) "Oil Price, Overleveraging and Shakeout in the Shale Energy Sector Game Changers in the Oil Industry."

Schwartz Center for Economic Policy Analysis and

Department of Economics, The New School for Social

Research, Working Paper Series 2015-7.

Published in Economic Modelling (2016) pp. 244-259

WORKING 


\title{
Oil Price, Overleveraging and Shakeout in the Shale Energy Sector - Game Changers in the OIL INDUSTRY
}

\author{
Arkady Gevorkyan* Willi Semmler ${ }^{\dagger}$
}

October 14,2015

\begin{abstract}
In recent years, we have observed significant growth in unconventional energy, shale energy, in particular in the United States. There was a boom, followed by a bust. The plunge in oil price triggered a prolonged bust in the energy sector. Which firms will benefit, and which will be squeezed out due to this persistent oil price decline? A new equilibrium is about to evolve under these conditions. In this paper, we develop a theoretical model that accounts for recent features in the energy sector. In particular, we focus on the shale energy companies and illustrate a trend toward a boom in external borrowing, overleveraging, and, now, a high risk of insolvency. With the use of a new method, called nonlinear model predictive control (NMPC), we show dynamic paths toward two equilibria: either a tight oligopoly or extensive competition, with the shakeout of some firms. This is also tracked by studying leveraging and overleveraging by groups of firms. We further undertake an empirical analysis using a vector error correction model (VECM), which helps identify the short- and long-term effects of those new challenges on the stock performance of the energy companies. The main finding is that large-cap companies are less dependent on the fluctuation in oil price than are mid- and small-cap firms.
\end{abstract}

JEL classification: D43, Q43, Q32

Keywords: Oil price, fracking, overleveraging, insolvency, NMPC, shale oil

\footnotetext{
*New School For Social Research, New York, NY, USA, email: gevoa020@newschool.edu

${ }^{\dagger}$ Henry Arnhold Professor of Economics, New School For Social Research, New York, NY, USA, email: semmlerw@newschool.edu
} 


\section{Introduction}

The recent boom-bust cycle in the energy sector - with, first, rising and high oil prices and, then, since mid-2014, declining oil prices settling at a very low levelhas created new challenges in the energy sector. The recent development in particular of innovation in oil extraction in the shale energy sector in the United States, called hydraulic fracturing (hydrofracking or fracking), has added to those new challenges. Now it appears that there are game changers that will persist for quite a while.

The new shale energy extraction method was developed during the period of the oil price boom. This method of extracting oil and gas involves horizontal drilling and fracturing of underground rock formations that contain deposits of crude oil and gas. Therefore, the fracking causes cracks and fissures in the rock formation, through which oil flows into a borehole, where it can be recovered. The magnitude of the development of shale oil and gas production since 1999 is significant. The United States is the main area in the world where shale oil and gas are produced. One of the major obstacles to development of shale in the other parts of the world is the substantial cost associated with drilling, but high oil price made it feasible. According to Kilian (2014), around 3.6 millions of barrels per day (mbd) in 2014 were produced in the United States using unconventional methods. Total average U.S. production in 2014 was $8.2 \mathrm{mbd}$.

The sustained increase in the price of crude oil since 2003 allowed a vast increase in production levels and the number of drilling rigs. Energy companies finance different investment projects by borrowing, issuing stocks and bonds, and using other methods. According to the Renaissance Capital Report (2014), about 25 initial public offerings (IPOs) have been made in the energy sector since 2010 every year until 2013. In 2014 alone, there were 30 energy IPOs that raised on average about $\$ 500$ million. The period from 2010 to 2014 is especially important in the current analysis, because this was when the price of the crude oil was on the rise, albeit with minor fluctuations. Such a relative stability in oil price, which served as a proxy for the value of the underlying assets, allowed energy companies to borrow and collateralize its debt based on the oil price. However, the decline in oil prices after mid-2014 revealed the debt burden of the energy companies. According to Domanski et al. (2015), debt held by the oil and gas sector rose from $\$ 1$ trillion in 2006 to $\$ 2.5$ trillion in 2014, a 2.5-fold increase.

However, companies in the shale oil and gas production sector are quite unique. The sector is actively developing. New companies emerged and developed in the early 2000s. At the same time large-capitalization (cap) players that have been in the energy sector for a long time are also getting into unconventional energy production. According to Kilian (2014), fracking companies have been gaining substantial market share and filling the fracking niche left by the large energy companies. Technological innovation has been one of the key factors making it possible for the smaller companies to enter the market. However, deteriorating oil prices can potentially put a hold on such developments. This explains the current study's interest in developments in the sector given the instabilities and recent 
downward trend in oil price.

The boom in the energy sector that started in 1999 appears to be coming to an end. Oil price is falling and is expected to persistent at this level for a while (Sutton 2014), indicating the bust period of the cycle . Excess amounts of borrowing, especially taken on by smallcapitalization companies during the period of high oil price, have also become evident. Furthermore, the market share that used to be owned by conglomerates was gradually taken over by the small- and mid-cap companies. Thus, one of the main questions that this study strives to answer is that which firms will benefit and which ones will be squeezed out of the business. The current bust is expected to be accompanied by a shakeout among participating firms.

The theoretical model and empirical analysis are structured around this study's main hypothesis. The developments in the shale oil and gas sector are analyzed using the model of incumbents and fringe firms. Even with technological innovation and development of new extraction methods, oil price remains a significant barrier to entry for new firms, thus at low oil price levels, large-cap companies have the potential to regain their market share and benefit from them in the long term.

Since the developments in this sector are relatively recent, the literature on fracking is rather limited. Gilje Ready, and Roussanov (2015) use the information contained in asset prices to evaluate the contribution of shale oil to the U.S. economy, with the main finding that technological shocks to shale supply capture a substantial fraction of total stock market fluctuations. Kilian (2014) expresses concerns regarding the uncertainty in the persistence and scope of the shale oil boom, given its rapid development in the past decade. Plosser (2014) and Domanski et al. (2015) study the increasing levels of debt held by the shale companies. While Domanski et al. (2015) provide an analysis of the sector borrowing as a whole, Plosser (2014) concentrates on the levels of deposits and the willingness of banks to lend to the shale oil companies. The development of shale oil became possible due to the high global oil prices, according to Alquist (2014). The author examines potential developments regarding the unconventional oil extraction levels and predicts a substantial increase in it. At the same time, it can be argued that high oil price has impeded the U.S. economic recovery by dampening consumer spending (Hamilton 2012). Overall, while there are studies on fluctuations in oil prices, until recently few studies discussed the economics of unconventional methods of oil and gas production. However, to the best of our knowledge, no studies have compared companies involved in shale oil and gas production with respect to fluctuations in oil price.

Our analysis looks at three groups of companies that are divided based on their market capitalization. The large-cap companies are those with market capitalization of $\$ 10$ billion or more, and mid-cap companies have market capitalization of $\$ 1$ billion to $\$ 10$ billion. The third group is small-cap companies, whose market capitalization is below $\$ 1$ billion. We select companies that have significant exposure to shale oil discoveries, as indicated by asset holdings listed in the firms 10-K filings. We also assume that large-cap companies are the dominant companies, whereas the small-cap companies are new entrants to the sector. 
The fate of the mid-cap group, which may be an unstable groupsome companies are falling and some are rising -is also studied in theoretical and empirical parts of the paper.

In the theoretical part of the paper, we present different scenarios of stability for companies in the shale energy sector. Before technological innovation, large energy companies controlled a big market share and were able to adjust production in response to the market conditions. With the introduction of fracking and the emergence of new entrants to the energy market, the market share started to shift, undermining the ability of the large firms to control their market share. Our model can lead to one of two scenarios: either a tight oligopoly or intense market competition. Current trends in oil prices has triggered a continuous shift in market share among the companies but also create entry barriers for new participants. This study represents a theoretical and empirical approach to those ongoing processes from the micro and macroeconomic perspective.

To study those issues empirically, the concept of excess leveraging (overleveraging), introduced by Stein (2012), is applied here to the shale energy companies that are studied, using balance sheets from those companies. The phase of accumulating debt usually begins with a period of tranquility, during which energy prices, the present value, and the net worth of companies are rising. Shale oil and gas companies commonly use crude oil prices as a proxy for the value of underlying assets. Recent declines in the price of oil have been causing significant financial burdens, raising insolvency risk, and creating potential contraction of the sector through shakeouts. With asset prices and net worth falling, the process has suddenly reversed, and severe borrowing constraints have begun to set in. Firms that previously took on debt while prices were high now find themselves unable to continuously borrow because price for oil is lower will be forced to find new ways to service their existing debt. Based on the data obtained from public companies, we calculate optimal and actual levels of the companies debt. We find that, while debt levels at large-cap companies are still within optimal bounds, mid- and small-cap companies are overleveraged and thus face potential insolvency.

Furthermore, our empirical methodology strives to explore patterns of price setting among companies with different levels of market capitalization. Financial time series of price changes for large-, mid-, and small-cap companies are examined, showing the effects of changes in the different underlying variables, including, but not limited to: crude oil, stocks, oil production, and a volatility index. The proposed vector error correction model (VECM) helps to reveal short-term linkages and long-term cointegrating relationships.

The remainder of the paper is structured as follows. Section 2 offers a theoretical model that presents the dynamic model of the energy market as whole with market share tipping point, separating dominant firms and new entrants. Section 3 presents key stylized facts in the researched data set and discusses the factors determining the levels of leveraging and overleveraging of the energy companies. An empirical analysis follows in Section 4 with a discussion of the data, pretesting, and the empirical methodology applied, as well as the empirical results. Section 5 is the conclusion, with Appendices containing further elaborations. 


\section{A dynamic model of the energy market: Dominance, loss of dominance, and shakeout}

In this section, we offer a short summary of the main features of the theoretical model. The model describes the energy market as comprising incumbents (the traditional energy firms) and the new entrants, which are supplying a new type of energy from shale. In addition to incumbents and new entrants, there is a third group in between, composed of companies that are either falling back or rising, so this group might be unstable. The following model is related to the one in Kato and Semmler (2011). Whereas the original model was set up for an infinite horizon decision and solved through a dynamic program, our version introduces a finite horizon and is solved using nonlinear model predictive control (NMPC). . We present three scenarios for each different price $p^{m}$.

Let us assume that the incumbents, or dominant firms, ${ }^{\text {D] }}$ use an objective function that maximizes the discounted future net revenues

$$
\max _{x} \int_{0}^{T} e^{-r t}[p q-C(q)-x-\varphi(x)] d t
$$

where $p$ is the price and $q$ is the output of the dominant group of energy firms, $C(q)$ is the cost of production and $C^{\prime}>0$. Assume a linear cost function for simplicity, $C^{\prime}=c>0$, where $1-c>0$. This implies that dominant firms can enjoy increasing returns from the production technology. $x$ is entry-deterring gross investment, and $\varphi$ is adjustment costs with properties $\varphi^{\prime}(x) \gtreqless 0$ for $x \gtreqless 0$ and $\varphi^{\prime \prime}>0$. In the model, the price of a unit of investment is 1 and $e^{-r t}$ is the discount factor for the cash flow. The dynamic state equation is:

$$
\dot{E}=x-\delta_{E} E
$$

where $E$ is the competition-deterring capital, ${ }^{1 /}, x$ the investment in it, and $\delta_{E}$ the depreciation rate of that capital. In eq. 2, competition-deterring capital can be represented by the dominant energy firms' efforts to restrict competition, for example, political lobbying, protection of innovations through patents, advertising efforts, and coalition formation. ${ }^{\text {. }}$. We conveniently assume that the price is a function of the market share of the dominant firms:

$$
p=p(s) \quad \text { for } 0 \leq s \leq 1
$$

where $p^{\prime}(s)>0, p(0)=p^{c}, p(1)=p^{m} \cdot p^{c}=\left(C^{\prime}(q)\right)$ and $p^{m}$ are the competitive and monopolistic prices respectively. The dominant firms face a downward-sloping market

\footnotetext{
${ }^{1}$ For the algorithm, see Grüne, Semmler and Stieler (2015)

${ }^{2}$ We assume here a profit-maximizing oligopoly oil cartel that can sufficiently cooperate to have one objective function, as a kind of joint oligopoly.

${ }^{3}$ In order to simplify the model we focus here only on the cost and revenue from the competition deterring actions as is assumed to be undertaken by the dominant energy firms.

${ }^{4}$ For further details see Kato and Semmler (2011).
} 
demand curve:

$$
q=s d(p) .
$$

The dominant firms revenue is $R(s)=p(s) s d(p)$. Many empirical studies in industrial organization have shown that there is a positive correlation between market share and rates of return. Therefore, we choose a set of parameters such that $R^{\prime}(s)>0$ for $0 \leq s \leq 1$.

The Lagrangian is written as

$$
\mathcal{L}=p(s) s(E) d(p)-C(q)-x-\varphi(x)+\lambda\left(x-\delta_{E} E\right)-\theta \dot{h} .
$$

We use the first-order conditions from equations 마며 and define the law of motion for the co-state variable $\lambda$ as follows:

$$
\begin{aligned}
\dot{\lambda}= & \left(r+\delta_{E}\right) \lambda-p^{\prime}(s) s^{\prime}(E) s(E) d(p) \\
& -\left\{p(s)-C^{\prime}(q)\right\}\left\{s^{\prime}(E) d(p)+s(E) d^{\prime}(p) p^{\prime}(s) s^{\prime}(E)\right\}+\theta \delta_{E} .
\end{aligned}
$$

From eq. [, one can derive the rate of investment for entry-deterring capital, which gives us the following differential equation:

$$
\begin{aligned}
\dot{x}= & \frac{1}{\varphi^{\prime \prime}(x)}\left[\left(r+\delta_{E}\right)\left(1+\varphi^{\prime}(x)\right)-p^{\prime}(s) s^{\prime}(E) s(E) d(p)\right. \\
& \left.-\left\{p(s)-C^{\prime}(q)\right\}\left\{s^{\prime}(E) d(p)+s(E) d^{\prime}(p) p^{\prime}(s) s^{\prime}(E)\right\}-\theta r+\dot{\theta}\right]
\end{aligned}
$$

We assume that there is a positive correlation between the market share of the dominant firms and their rates of return.

The system has state-dependent dynamic properties with two attractors or a sole attractor. Specific functions for the market price and the market demand should be defined. We choose linear functions for simplicity.

$$
\begin{gathered}
p(s)=p^{c}+\left(p^{m}-p^{c}\right) s \quad \text { for } 0 \leq s \leq 1 \\
d=b-a p
\end{gathered}
$$

$p^{c}, p^{m}, b$ and $a$ are chosen such that $R(s)=p(s) s d(p)$ monotonically increases for $0 \leq s \leq 1$. This could happen for a relatively small difference $\left(p^{m}-p^{c}\right)$, large $b$ and small $a$. We use a default parameter set as:

Table $\mathrm{U}$ summarizes the results for various markups, determined by $p^{m}=8,7,6$. The exact markup of the dominant firms over the competitive price is given by $\left(p^{m}-p^{c}\right) s$ through eq. 8. The first case in Table $\mathbb{0}$ has two attractors and one repellor (SS2). SS3 shows a high steady state for E(8), with a high markup. The second version of the model,

\footnotetext{
${ }^{5}$ See, for example, Weiss (1963)
} 
Example: (DefaultB) $r=.02, \delta_{E}=.15, \rho=5, \chi=10, c=.001, \alpha=.5, p^{m}=8,7,6 p^{c}=2, b=10, a=.5$

\begin{tabular}{|l|l|l|l|}
\hline & SS1 (attractor) & SS2 (repellor) & SS3 (attractor) \\
\hline Entry-deterring capital E(8) & 0 & 30.05 & 37.4 \\
\hline Entry-deterring capital E(7) & 0 & 32.5 & 35.5 \\
\hline Entry-deterring capital E(6) & 0 & 0 & 0 \\
\hline
\end{tabular}

Table 1: Parameters and steady states

$\mathrm{E}(7)$, shows a lower steady state SS3 due to a lower markup. The third variant of the model, E(6), has an even lower markup and only one steady state, namely, the zero SS.

Moreover, the first two variants of the model have one repellor in the middle, SS2. The interpretation of this is that after the incumbent moves with its market share above SS2, it will dominate the market persistently and cannot be challenged, unless there is a new technological development or government intervention, in which new energy competition can emerge.

As the above model shows, after the incumbents have a large market share, it is very difficult for fringe and mid-cap energy firms to enter the market and to compete with the dominant firms. This seems to have been the situation in the energy industry before oil prices declined considerably. The advent of new technology - as well as unprecedented government support for new energy technology, such as renewable energy - has reduced the markup for the dominant energy firms to allow new fringe firms to enter the energy market. Also, such an environment might be beneficial for the energy companies in the middle group. The three scenarios in Table $\mathbb{0}$ are replicated dynamically in three figures. ${ }^{\mathbf{6}}$

In Figure $\mathbb{0}$, we observe multiple equilibria. The dominant firms will achieve a large market share, even with low initial conditions. Because the markup is high, $p^{m}=8$, it will achieve a high attracting market share, reached from the initial condition $\mathrm{E}(0)=29.5$. Only for initial conditions below a threshold $\mathrm{E}(0)=29.5$ will the dominant firms lose market share, as in the declining trajectories below $\mathrm{E}(0)=29.5$, due to competition.

In Figure $\nabla$ we also see multiple equilibria. The dominant firms will achieve a large market share, only with a higher initial condition. The markup is still high, indicated by $p^{m}=7$. The dominant group of energy firms will achieve a high attracting market share, reached only from the initial condition $\mathrm{E}(0)=32.5$. Yet already below a threshold of $\mathrm{E}(0)=32.5$, the dominant oligopoly will lose market share, as in the declining trajectories below $\mathrm{E}(0)=32.5$, due to competition from the middle group and new entrants.

In Figure [] we no longer see multiple equilibria. The dominant firms can start with a large market share, and with high initial conditions, yet because the markup is low, as indicated by $p^{m}=6$, the dominant group of energy firms will continuously lose market share, and, due to competition, its market share will shrink over time. This was the situation in the second half of 2014 and first half of 2015, when the oil cartel lost market share and

\footnotetext{
${ }^{6}$ For the solution of the model, we use NMPC, as proposed by Grüne et al. (2015)
} 


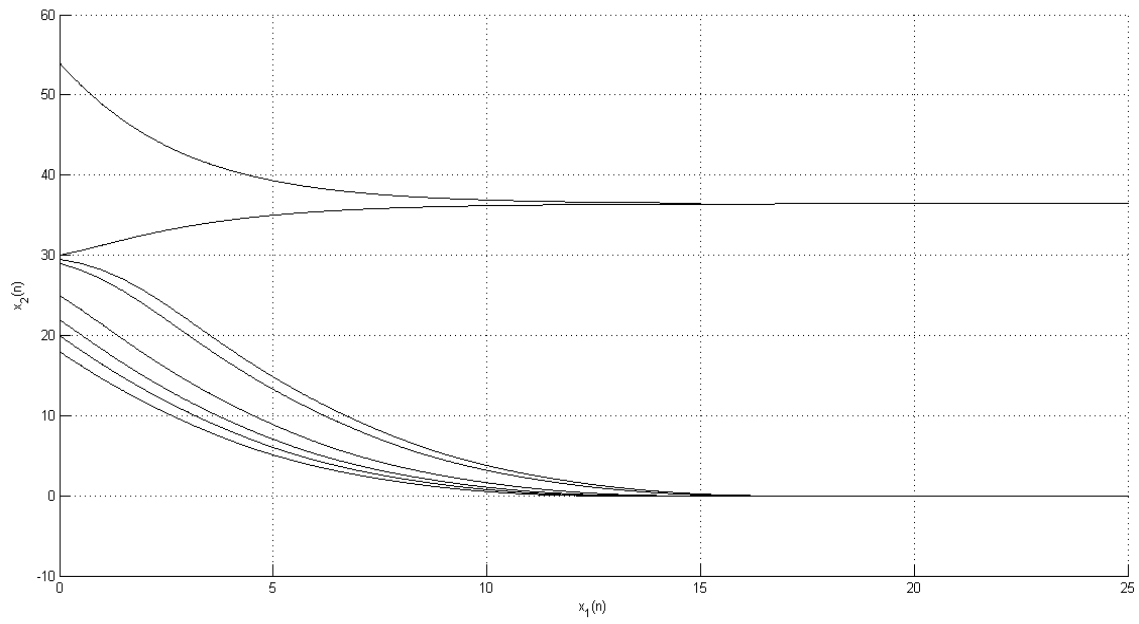

Figure 1: Multiple equilibria; upper two trajectories, convergence to dominant firms' market share, higher markup, high attracting market share, reached from initial condition $\mathrm{E}(0)=29.5$; declining trajectories represent declining market share due to competition below threshold $\mathrm{E}(0)=29.5, p^{m}=8$.

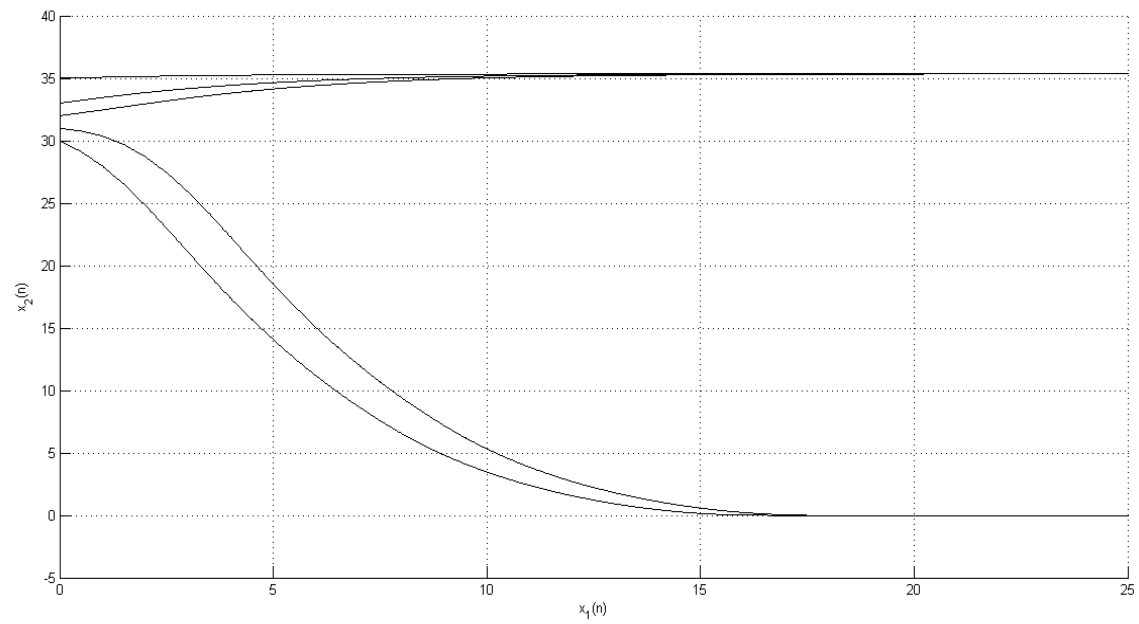

Figure 2: Loss of dominance, market share shrinking, even with large initial capital and market share, loss of dominance due to lower markup, $\mathrm{E}(0)=32.5, p^{m}=7$. 


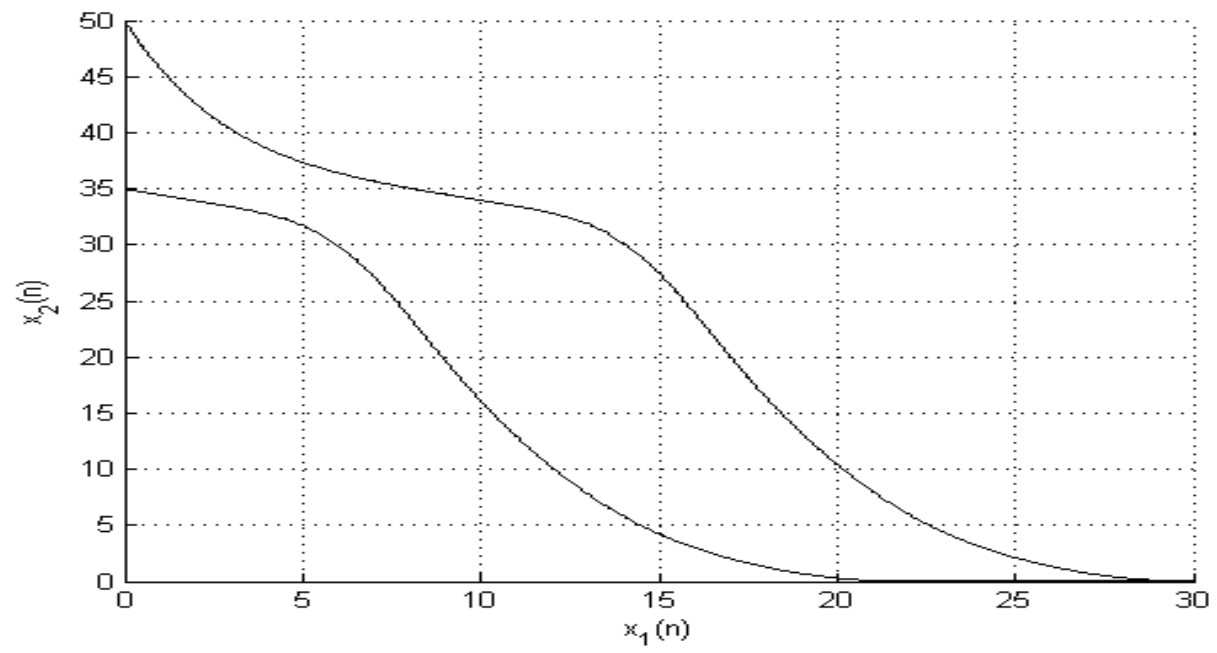

Figure 3: Total loss of dominance, market share shrinking, even with large initial capital and market share, due to lower markup, $p^{m}=6$, two different initial conditions.

market power and the new and middle and small shale energy firms increased their market share.

It is important for incumbents to have control over the market share, when markups fall (the three scenarios of $p^{m}$ described above); otherwise, incumbents market share will shrink. At the same time, such external factors as high oil price served as good collateral for new entrants and the middle group over the long term and provided those companies with necessary funds. In this process, the incumbents and the new entrants became competitors. However, the new entrants and middle group companies, given their large exploration and extraction costs relative to falling market prices, also faced serious difficulties because they came into the market last, as marginal firms with high production costs. Those companies had to borrow funds - in a low credit-cost market environment - but built up large debt, which could be repaid only if the oil price was high. All three groups - the incumbents, the middle group, and the new entrants - were attempting to sustain the production levels of oil to keep their revenue flowing. Yet, with the oil price falling further, a shakeout is expected among the new entrants. When the model predicts a shakeout, it can create this effect in several ways: either the dominant firms are declining and small- and mid-cap firms rise, or the reverse, small and midsize companies are squeezed out through insolvency. Which way it will go is an empirical question, which is examined next. 


\section{Empirics: Overleveraging, plunging oil price, and shakeout}

When oil price is high, overleveraging is usually not a problem. But the plunge in oil price makes the excessive leveraging visible. When oil price is high, new projects and new technologies to boost production levels are frequently financed through extensive borrowing. Companies that are investing in shale oil and gas production tend to increase their debt in order to keep drilling. Thus, for most companies, the profitability of their operations and their leveraging are closely linked to the price of West Texas Intermediate (WTI) crude oil. The break-even price for many shale companies is from $\$ 70$ to $\$ 90$ per barrel. Therefore, prolonged periods when the price is below that level could lead to continuous instability in the entire sector (World Bank, 2015).

Figure 4 shows the dynamics of WTI crude oil prices over the past 15 years. After 2009, the price of oil was consistently over $\$ 60$ per barrel until the second half of 2014, with the highest point at $\$ 106$ per barrel. During this period, shale companies had easy access to borrowed funds, allowing them to explore deposits and expand production. However, sharp decreases in oil price forced those companies to adjust quickly and either borrow more or trim their investment projects. This scenario fully corresponds to the developed theoretical model and its dynamics.

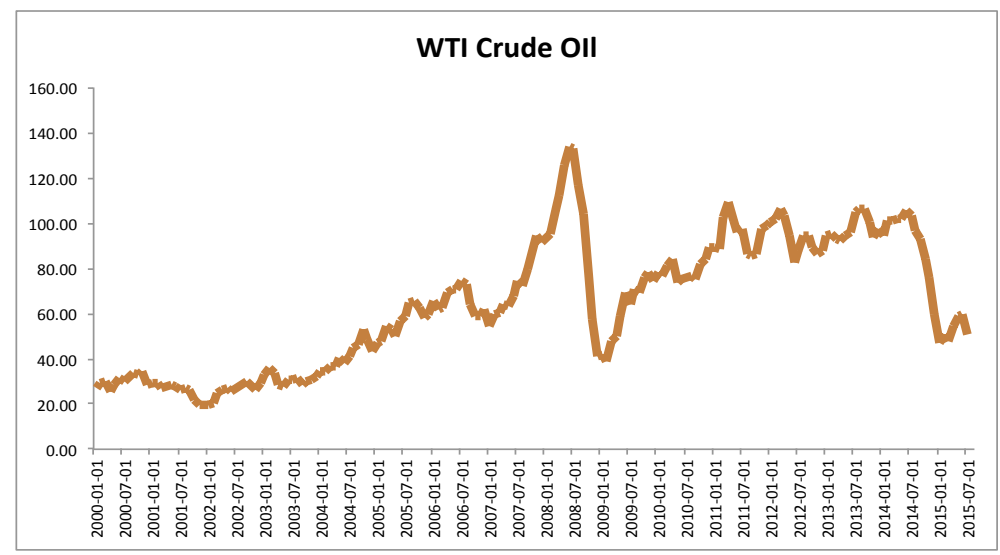

Figure 4: WTI Crude Oil Price, 2000-2015 period

Source: US Energy Information Administration

According to a report by the US Energy Information Administration (EIA 2014), since March 31, 2014, cash from operations for 127 major oil and natural gas companies totaled $\$ 568$ billion, and major uses of cash totaled $\$ 677$ billion. Therefore, the shortfall, according to the report, $\$ 106$ billion, was filled by a net increase in debt and $\$ 73$ billion was raised from the sale of assets. The gap between cash from operations and uses of cash widened dramatically since 2011. The increase in the gap is about 580\% (from $\$ 18$ billion in 2010 
to $\$ 106$ billion in 2014$) !^{\square}$.

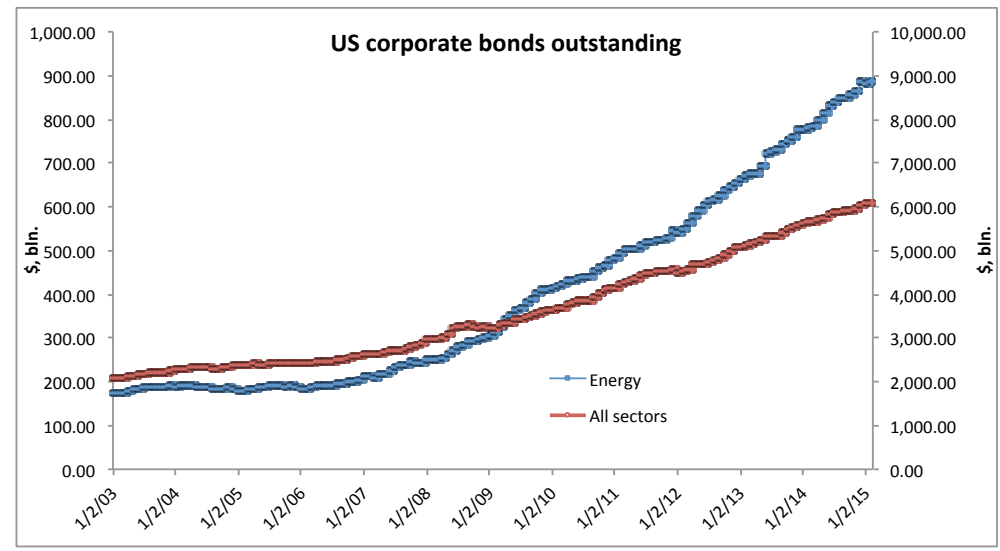

Figure 5: US corporate bonds outstanding, 2003-2015 period

Sources: Bloomberg; Thomson Reuters Worldscope; BIS calculations.

Figure 5 indicates that, since 2008, companies in the energy sector have borrowed increasingly in bond markets. The pace at which energy companies borrowed far exceeded that in other sectors.

A destabilizing mechanism usually results from a linkage of asset prices and levels of borrowing, as emphasized by Stein (2012). The analysis developed in that study on the banking sector can be applied to the shale sector as well. When oil price is above the break-even point (which may depend on the company size), shale producers will enjoy capital gains above normal returns. This fact leads companies to invest more in their own production and, therefore, increase their debt. This process certainly boosts oil and gas production, giving rise to increasing net worth. Next, the level of debt increases, as capital gains and excess returns on capital rise as well. In that case, capital gains are the stochastic factor dependent on fluctuation in oil price. Therefore, when capital gains shrink or become negative with plunging oil prices, the level of leveraging starts to exceed optimal levels, and overleveraging occurs, which can have downward-amplifying effects.

Based on the analysis in Schleer, Semmler, and Illner (2014), we introduce a new measure of overleveraging, which is present when borrowing exceeds debt capacity. In our analysis, optimal debt represents debt capacity levels. Optimal debt, as calculated by Stein (2012), is determined by maximizing the difference between the return and risk term in the context of a model of return-risk trade-off; for a detailed description, see Stein (2012, ch. 4.9).

It is also important to note that although optimal debt is the preferred level of debt to be held by the company, actual debt should also be considered. Normally, actual debt is calculated as the amount of long-term debt over total assets.

\footnotetext{
${ }^{7}$ http://www.eia.gov/todayinenergy/detail.cfm?id=17311
} 
Calculation of optimal debt is based on the use of the simplified case of logarithmic utility, also presented in Stein (2012, p.71), where the optimal debt ratio $f^{*}$ maximizes the difference between the mean $M(f(t))$ and risk $R(f(t))$, which represents a mean-variance formulation. Thus:

$$
f^{*}=\operatorname{argmax}[M(f(t))-R(f(t))]=\left[(a(t)+\beta(t)-i)-\left(\sigma_{p}^{2}-\rho \sigma_{i} \sigma_{b}\right)\right] / \sigma^{2}
$$

With the calculations presented in Stein (2012, appendix B), the optimal debt or leverage ratio is defined as follows:

$$
f^{*}(t)=\left[(r-i)+\beta-\alpha y(t)-\frac{1}{2} \sigma_{r}^{2}+\rho \sigma_{i} \sigma_{r}\right] / \sigma^{2}
$$

where $\beta$ is a trend productivity of capital, being deterministic, $r$ is the capital gains, $i$ the borrowing rate, and $y(t)$ is the deviation of capital gains from its trend, $\sigma_{i}^{2}$ is the variance of the interest rate, $\sigma_{r}^{2}$ is the variance of capital gains, and $\rho$ defines the correlation of $i$ and $r$. Moreover, $\sigma$ is a risk element given by $\sigma^{2}=\sigma_{i}^{2}+\sigma_{r}^{2}-2 \rho \sigma_{i} \sigma_{r}$.

In order to calculate eq. $\square$, data was collected from the $10-\mathrm{K}$ and $10-\mathrm{Q}$ reports of individual companies. The data are quarterly, from Q1 2011 to Q1 2015. Relying on the methodology provided by Stein (2012) and Schleer et al. (2014), capital gains are calculated as quarterly growth rates of the stock market capitalization of the company. Market cap is calculated as the product of the stock market price and the outstanding common shares. For $i$ we use the five-year Treasury constant maturity rate interest rate. The productivity of capital $\beta$ is obtained by dividing the company's gross income (revenue minus administrative expenses) by the companys assets.

For eq. 미 we also calculate $\rho$ - the correlation factor - and the productivity trend $\beta$. These values, along with standard deviations and variance of the interest rate and capital gains, are constant values over the period. Finally, according to the procedure in Schleer et al. (2014), the optimal debt ratio is normalized by calculating the difference between the optimal debt ratio and the mean over the period and dividing it by the standard deviation. Actual debt is also normalized to match its unit to the one of the optimal debt ratio.

In the following, we present results for three groups of energy companies. We divide our sample of companies into three groups: large-, mid-, and small-capitalization companies. This breakdown also corresponds to the incumbents, new entrants, and middle group companies analysis presented in Section 2. In our empirical study here, each individual group has five companies, according to their market capitalization. The largecap group includes: Occidental Petroleum Corporation (OXY), Devon Energy Corporation (DVN), ConocoPhillips (COP), Chevron Corporation (CVX), and ExxonMobil Corporation (XOM). The mid-cap group includes EOG Resources (EOG), Whiting Petroleum Corp. (WLL), Pioneer Natural Resources Co. (PXD), Continental Resources (CLR), and Chesapeake Energy Corporation $(\mathrm{CHK})$. Finally, the small cap group includes EXCO Resources 
(XCO), Magnum Hunter Resources Corp. (MHR), EV Energy Partners LP (EVEP), Halcon Resources Corporation (HK), Sanchez Energy Corporation (SN), and Penn Virginia Corporation (PVA).

In order to combine these separate groups of companies, we use the weighted average market capitalization index time series. The index is created on the basis of the market capitalization of the companies. Appendix A reports detailed results for each company in the index.

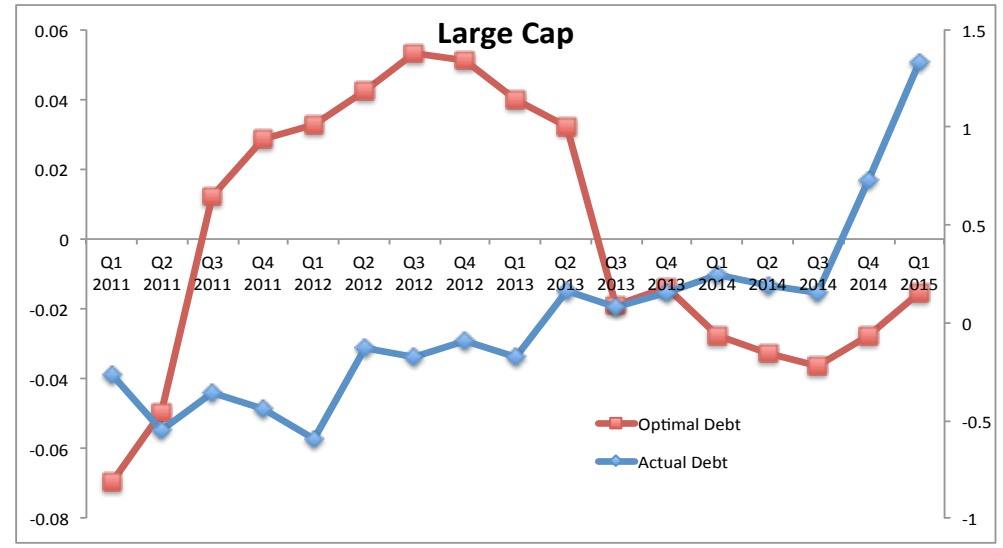

Figure 6: Large-Cap Firms Q1 2011-Q1 2015

Figure 6 presents results obtained for the large-cap companies. The figure shows increasing levels of actual debt, which is currently at higher than optimal levels. However, the scale of the actual and optimal debt is quite small for large-cap companies, taking into account their market capitalization. While oil price was high, actual debt was growing but not greatly. Large-cap firms did not need to borrow extensively at the time, but after 2014 actual debt started to grow. One explanation for this growth in actual debt is deteriorating market conditions, especially the plunge in oil prices.

The scenario for mid-cap companies in Figure $\mathbf{\square}$ is slightly different, in that actual debt grew when oil prices were high. Mid-cap companies have market capitalization between $\$ 1$ billion and $\$ 10$ billion but can be unstable, with market capitalization above $\$ 10$ billion or below $\$ 1$ billion at some point in the past ten years. We consider market capitalization of the companies included in the mid-cap group as of July 1, 2015. As seen in the figure, the level of debt on the left-hand scale for these companies is higher than in the Figure $\mathbf{6}$. Beginning in the second half of 2014, actual debt for mid-cap companies started to grow and is currently above the optimal level.

Figure 8 shows the difference between actual and optimal levels of debt for small-cap companies. Starting in 2013, small-cap companies became overleveraged. The gap between the two indices widened, which could be attributed to the high dependence of small-cap firms on the persistently high oil price. 


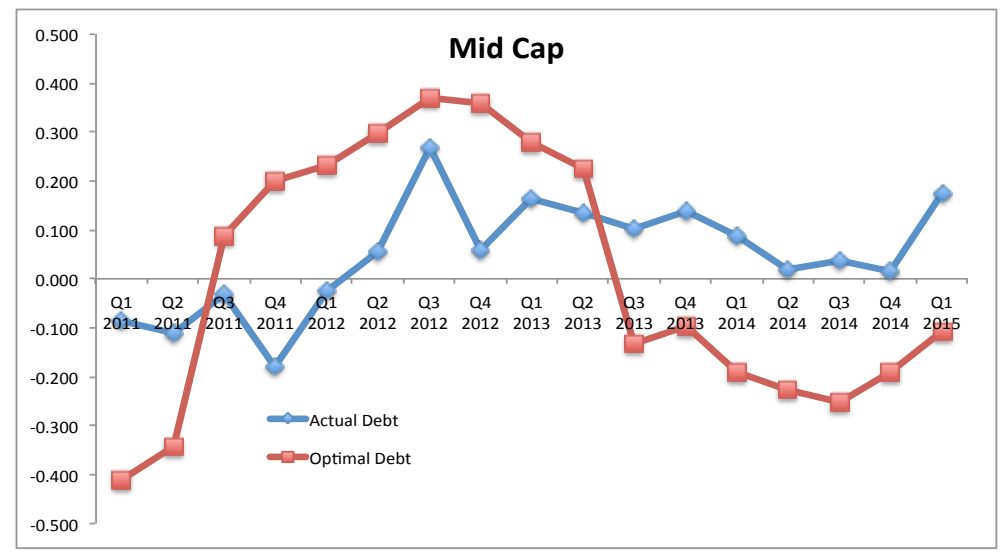

Figure 7: Mid-Cap Firms Q1 2011-Q1 2015

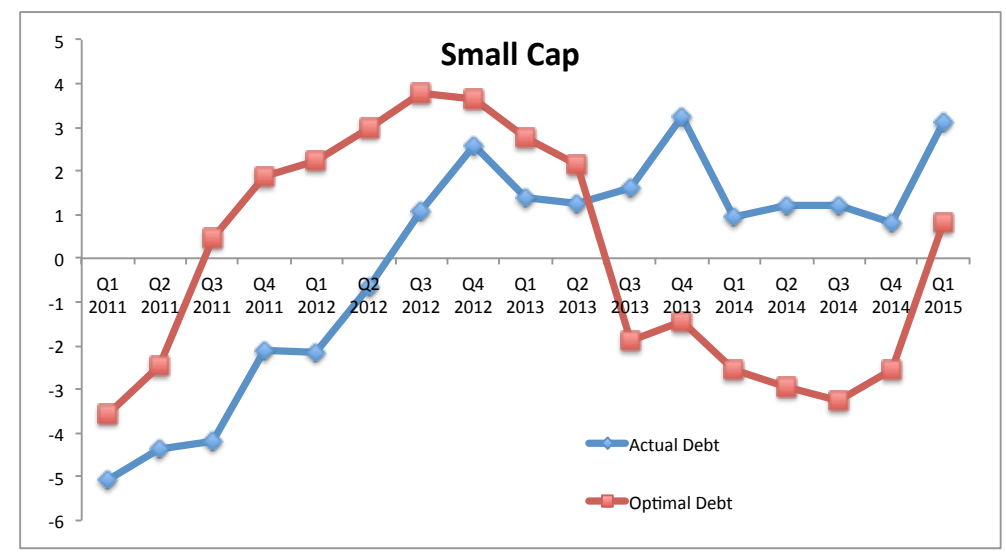

Figure 8: Small-Cap Firms, Q1 2011-Q1 2015

Figure $\mathbf{Q}$ illustrates the difference between actual and optimal levels of leveraging for all three group of companies. Although the large-cap group shows relative stability, the midand small-cap companies fall into instability in the level of borrowing. The level of leveraging is shown for the small cap companies on the left-hand axes, and the level is shown for large and mid cap companies on the right-hand scale. The level of debt is significantly higher for the small-cap companies than for mid- and large-cap companies. The vulnerability indicated by overleveraging of mid- and small-cap companies will certainly have an effect on their market share of oil production. In order to repay their debt in an environment of low oil price, such companies will need to downsize production levels by liquidating real capital. Such a change in production levels will also affect the total market share of those companies. Thus, as seen in our theoretical model in Section 2, long-term low oil prices might allow large-cap companies to slowly regain the market share they had earlier ceded to 


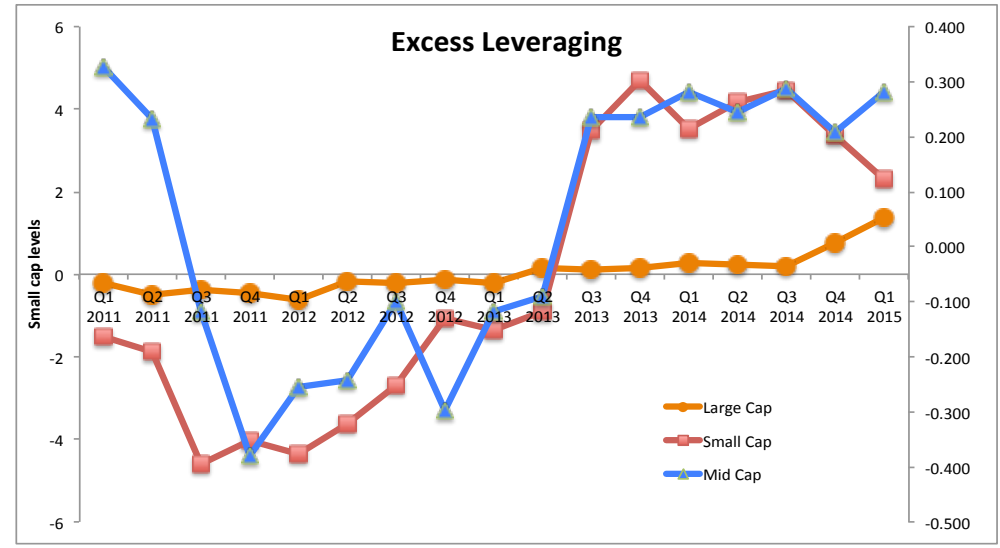

Figure 9: Excess Levels of Leveraging, all three groups

mid- and small-cap firms that now struggle because of their high debt and overleveraging.

Overall, the increase in the level of debt for small- and mid-cap companies occurs during the 2010-2014 period, which is a time of relative stability in oil prices. By contrast, the majority of large-cap companies did not borrow substantial funds until the recent plunge in oil price. This is clearly shown in Figures $\mathbf{\square}$ and $\mathbf{8}$, compared to Figure $\mathbf{9}$. The levels of actual and optimal debt for two groups (small- and mid-cap) are different, however, their dynamics are similar. This divergence of optimal and actual debt is likely to be driven by the fall in oil price and the longevity of this trend. The current analysis corresponds to the results obtained from the theoretical model in Section 2. The model's implications are further explored in the next section.

\section{Time-series Study}

\section{Methodology and Data}

Next we turn to a time-series methodology and study the dependence of shale energy companies on the level of the price of oil. We present an analysis for the same companies examined in Section 2. Companies are grouped based on their market capitalization in the weighted average index. The aim of this empirical analysis is to determine variables that have long- and short-term effects on different companies in the same sector. We analyze a mix of variables that are strong drivers of the performance of the stock prices of individual companies and the sector as a whole.

In order to adjust for the effect of macroeconomic factors, the weighted average timeseries index is first divided by the corresponding S\&P 500 data. We use monthly data in our empirical estimations covering the period from December 1, 2010, to July 1, 2015. In order to determine $\mathrm{I}(1)$ processes in the data, augmented Dickey-Fuller (ADF) tests were 
conducted. All the analyzed variables show a unit root, therefore, the log difference was applied on the time series. ADF test results are omitted for the sake of brevity and are available upon request.

The methodology that allows us to determine short- and long-term effects on the dependent variable is a vector autoregressive model (VAR). However, in cases of established cointegration across a series, a vector error correction model (VECM) should be employed. Multivariate forms of Akaikie information criterion (AIC) and the Schwartz Bayesian criterion (SBC) are first applied in order to determine the lag length. Then, we proceed with the cointegration analysis, which was first introduced by Johansen (1988), with hypothesis testing for parameters in the possible cointegration, and further developed by Johansen and Juselius (1990) with an exogeneity test. The Johansen test allows us to determine the number of cointegrating relations in the regression.

The general form of the system, where $\Delta=(1-L)$, and $L$ is the lag operator:

$$
\Delta y_{t}=\Pi y_{t-1}+\sum_{i=1}^{\rho-1} \Gamma_{i} \Delta y_{t-i}+\epsilon_{t}
$$

where $y_{t}$ is an $\mathrm{I}(0)$ vector, $\Pi=\sum_{j=1}^{j=\rho} A_{j}-I_{k}$ is the long-run effect and $\Gamma_{i}=-\sum_{j=i+1}^{j=\rho} A_{j}$ is the short-run relationship among variables.

Adapting eq. ए2 for our analysis, the model, for our variables at hand, has the following form:

$$
\begin{aligned}
& \Delta y_{t}=\Pi y_{t-1}+\sum_{i=1}^{\rho-1} \gamma_{1, i} \Delta \text { price }_{t-i}+\sum_{i=1}^{\rho-1} \gamma_{2, i} \Delta v x x_{t-i}+\sum_{i=1}^{\rho-1} \gamma_{3, i} \Delta s p y_{t-i} \\
&+\sum_{i=1}^{\rho-1} \gamma_{4, i} \Delta \text { uso }_{t-i}+\sum_{i=1}^{\rho-1} \gamma_{5, i} \Delta \text { interest }_{t-i}+\sum_{i=1}^{\rho-1} \gamma_{6, i} \Delta \text { oil__production } \\
& t-i \\
& \\
&+\sum_{i=1}^{\rho-1} \gamma_{7, i} \Delta \text { shale_production }_{t-i}+\sum_{i=1}^{\rho-1} \gamma_{8, i} \Delta \text { ipi }_{t-i} \epsilon_{t}
\end{aligned}
$$

The left-hand side is the weighted index average, which is presented for large-, mid-, and small-cap companies. On the right-hand side: cap - represents the large-, mid-, and smallcap firms, respectively; $v x x$ - the exchange traded fund index that offers exposure to daily rolling VIX futures contracts; spy - index that corresponds to the price and yield performance of the S\&P 500 index; uso - United States Oil fund is a commodity pool and mainly serves as a proxy for movement in the price of crude oil; interest - is a fiveyear Treasury inflation-indexed security (constant maturity); oil_production - crude oil production in the United States; shale_production - production of shale oil in the United 
States (data is accumulated from different regions into a national indicator); ipi - industrial production index of the United States ${ }^{\mathbb{B}}$.

\section{Main Results}

The results obtained are important for our analysis and provide a full picture of the shale sector in a distressed environment (with low oil prices). We provide a comparison of the results from our estimated regressions. A system with four lags is sufficient to eliminate indications for dynamic error specification based on the smallest AIC values. Cointegration test results are presented in Tables $\nabla$ to $⿴$, which show that the hypothesis of no cointegration vectors can be rejected. The baseline Johansen procedure performs a maximum likelihood test on the trace of the $r$ largest (in absolute value) eigenvalues, where $r$ is the number of cointegrating relations under investigation (Johansen 1988). The null hypothesis of this trace test is that the system has, at most, $\mathrm{r}$ cointegrating relations. Consecutively comparing the tests for $r=0, \ldots, K$, where $K$ is the number of variables being cointegrated, enables us to determine the number of cointegrating relations. According to Tables $\square$ and $\boldsymbol{\nabla}$, there are four cointegrating relations. There are three cointegrating relations for mid-cap companies, reported in Table $\mathbf{3}$.

\begin{tabular}{clc|cc}
\hline Trace Statistics & & & Critical Values & \\
\hline$H_{0}$ & $H_{A}$ & Trace & $5 \%$ & $1 \%$ \\
$r=0$ & $r=1$ & 183.0896 & 124.24 & 133.57 \\
$r<=1$ & $r=>2$ & 135.2283 & 94.15 & 103.18 \\
$r<=2$ & $r=>3$ & 96.5726 & 68.52 & 76.07 \\
$r<=3$ & $r=>4$ & 61.6855 & 47.21 & 54.46 \\
$r<=4$ & $r=>5$ & $31.8354^{*} 1$ & 29.68 & 35.65 \\
$r<=5$ & $r=>6$ & $12.7046^{*} 5$ & 15.41 & 20.04 \\
\hline \hline
\end{tabular}

Table 2: Johansen cointegration trace test (large cap)

The error correction model's estimation results are reported in Table 1 for large-, mid-, and small-cap companies. Table 1 presents coefficients of short-run dynamics with standard errors (in parentheses) and significance levels. Due to the strong dynamics of the ongoing processes, our primary focus is on the short-run effects. The underlying hypothesis is that the results may shed some light on the heterogeneity of the shale production sector, in particular on the effect of the severe fall in oil prices on different companies. Although new entrants to the industry (small-cap) need to compete and obtain a substantial market share, collapsing crude oil prices are making this task difficult. At the same time, big corporations

\footnotetext{
${ }^{8}$ Data were obtained from following sources: Bloomberg, Yahoo Finance, U.S. Energy Information Administration, Federal Reserve Bank of St. Louis, IMF, and World Bank databases.
} 


\begin{tabular}{clc|cc}
\hline Trace Statistics & & & Critical Values & \\
\hline$H_{0}$ & $H_{A}$ & Trace & $5 \%$ & $1 \%$ \\
$r=0$ & $r=1$ & 210.0201 & 124.24 & 133.57 \\
$r<=1$ & $r=>2$ & 145.7248 & 94.15 & 103.18 \\
$r<=2$ & $r=>3$ & 89.8826 & 68.52 & 76.07 \\
$r<=3$ & $r=>4$ & $51.6593^{*} 1$ & 47.21 & 54.46 \\
$r<=4$ & $r=>5$ & $29.4772^{*} 5$ & 29.68 & 35.65 \\
\hline \hline
\end{tabular}

Table 3: Johansen cointegration trace test (mid cap)

\begin{tabular}{|c|c|c|c|c|}
\hline \multicolumn{3}{|c|}{ Trace Statistics } & \multicolumn{2}{|c|}{ Critical Values } \\
\hline$H_{0}$ & $H_{A}$ & Trace & $5 \%$ & $1 \%$ \\
\hline$r=0$ & $r=1$ & 177.0113 & 124.24 & 133.57 \\
\hline$r<=1$ & $r=>2$ & 124.1095 & 94.15 & 103.18 \\
\hline$r<=2$ & $r=>3$ & 80.2726 & 68.52 & 76.07 \\
\hline$r<=3$ & $r=>4$ & 55.254 & 47.21 & 54.46 \\
\hline$r<=4$ & $r=>5$ & $34.7986^{*} 1$ & 29.68 & 35.65 \\
\hline$r<=5$ & $r=>6$ & 16.3745 & 15.41 & 20.04 \\
\hline$r<=5$ & $r=>6$ & $1.6048^{*} 5$ & 3.76 & 6.65 \\
\hline
\end{tabular}

Table 4: Johansen cointegration trace test (small cap)

are not affected as much by the sluggish oil price but, rather, by changes in their market share.

Table 1 considers changes in the stock price of main shale energy companies during the December 2010-July 2015 period for which there are data on volatility, market, oil prices, interest rates, and the level of oil production. Column 1 shows the large-cap energy companies weighted price index for the variables presented in eq.[3]. The same information is shown for the mid- and small-cap companies in columns (2) and (3), respectively. According to the results, the VIX variable has a negative effect on the mid- and small-cap companies, but large-cap firms are not affected much by fluctuation in the index. One potential explanation for this unimportance of the VIX index on large-cap firms is that, in the past five years (2010-2015) this index has not experienced fluctuations as wide as those during the Great Recession, 2008-2009. As mentioned in the literature, the time VIX index is mostly in the same range as it has been for the past five years. Thus, during a relatively stable period, the VIX still has a negative effect on mid- and small-cap companies. Also, according to our assumptions, spy variable is statistically significant for large-cap companies in column (1). Small-cap companies are not affected by fluctuations in the stock market, which can be interpreted from the way that market shocks have a limited effect on small-cap companies in column (3). 


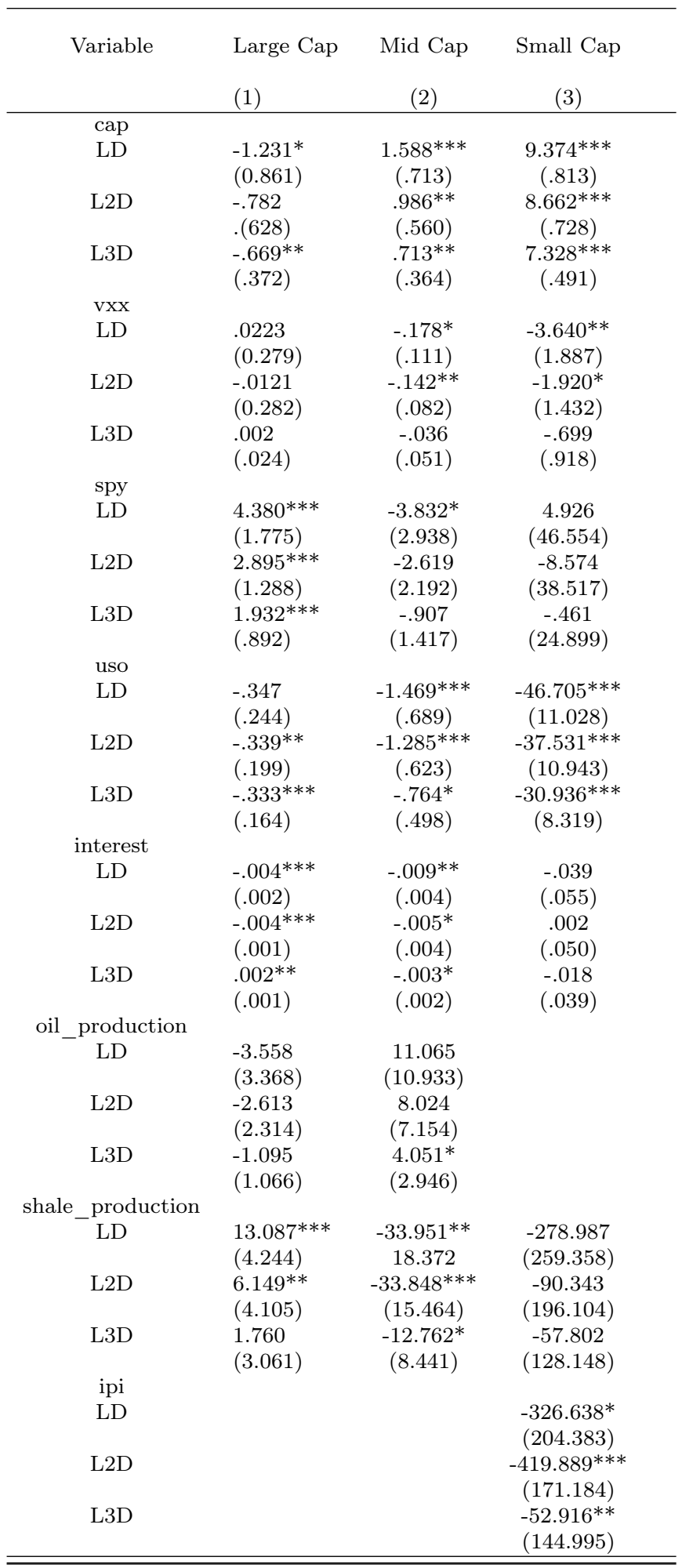

Table 5: VECM estimation results

Author's calculations. Standard errors are reported in round parentheses. Significance levels $*, * *, * * *$ indicate rejection of the null hypothesis with $10 \%, 5 \%$ and $1 \%$ confidence, respectively. 
Changes in oil price, which in our model are represented by the uso index, demonstrate a statistically significant inverse relationship with the changes in the prices of all companies in the shale energy sector. According to Table 5 , these results are strongly supported by the small-cap sector, which appears to be heavily dependent on oil price. Large-cap companies are negatively affected by the uso on the basis of two or more lags.

The VECM short-run relationship between stock prices of large-cap companies and interest rates is found to be inversely related and statistically significant. One interpretation is that large companies are less constrained than small companies in borrowing. However, the previous section indicates that the level of debt at small-cap companies is much higher than it is at large-cap firms. Interest rates are also having an effect on mid-cap companies.

The Industrial Production index variable was added to the estimations of small-cap companies (column 3), as an alternative method, indicating a positive association. Oil production levels at a national scale do not have great statistical significance on the regressions.

The level of shale energy production sheds some additional light on the interconnection of the level and the price changes at large- and mid-cap companies. While large-cap companies are increasing their market share of shale production, mid-cap companies are having difficulty in sustaining it at an optimal debt level and need to adjust their production scale as oil prices change. According to Crooks (2015), US exploration and production companies sold under $\$ 1$ billion in assets in July and August, whereas $\$ 3.7$ billion in shares was sold in the second quarter and $\$ 10.8$ billion in the first quarter of 2015 . This tendency is a clear shift in the market share, which results from having the WTI crude oil price below $\$ 60$ for a prolonged period (Sutton 2014).

Next, we present the diagnostic test results for the properties of the integrated systems defined in eq. [3]. The diagnostic test includes testing for residual serial autocorrelation, homoscedasticity, and normality. Table6 presents the Breusch-Godfrey Lagrange multiplier test for up to four lags for all three models with the null hypothesis of no autocorrelation. All the regression results indicate no serial correlation. A Jacques-Bera normality test was also conducted. For all the regressions, the normality test cannot be rejected and also reveals the correct numbers of cointegrating equations (results are omitted because of space constraints).

Appendix Figure $\mathrm{A4}$ offers a graphical representation of the empirical results via an orthogonal impulse response function (IRF), which is one way to represent long-term relations of different variables. Results for large- and mid-cap firms show a similar pattern, which suggests high initial share price volatility following initial shocks in the model's variables. IRF for small-cap companies is also shown in Appendix Figure A4. The industrial production index and interest rates demonstrate a similar pattern in the analysis.

Overall, our results correspond to the model in Section 2 and the analysis on overleveraging in the shale oil sector in Section 3. This suggests that, because of the great dependence of small companies on crude oil price, the further development of fracking and shale energy production in the future will depend on the large firms. The mid-cap companies are also suffering from the decrease in oil price, and their future will depend on how long this price 


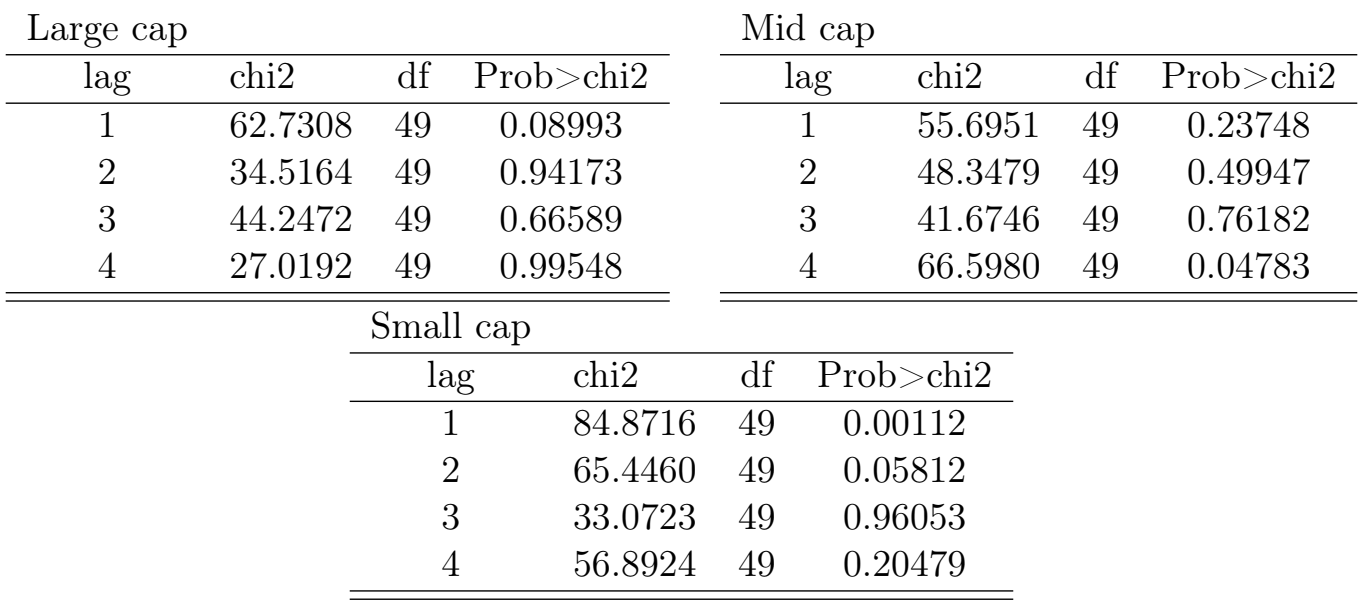

H0: no autocorrelation at lag order

Table 6: Lagrange multiplier test results

decrease lasts. Thus, according to our empirical results, the market dynamics point to a shakeout among small- and mid-cap companies, but not large-cap companies, despite their temporary vulnerability.

\section{Conclusion}

The declines in energy prices and excess leveraging by shale energy companies expose those companies to great instability. Shale energy production is currently in a bust period, with falling oil price. Overleveraging and the risk of insolvency have risen, in particular among the mid- and small-cap companies. In the current study, we try to replicate this analysis in a theoretical model that provides thresholds and tipping points for market share dynamics in different scenarios based on the markup of the companies. We also introduce a dynamic model on optimal or sustainable levels of leveraging. Moreover, we provide a measure for overleveraging, which is the difference between actual and optimal debt levels. Lastly, we introduce an empirical analysis that allows us to look at the different groups of companies and the short- and long-term effects of different variables on stock performance.

The price of crude oil began a steady rise in 2003, with some fluctuation during the 2008-2009 economic crisis. Until the second half of 2014, mid- and small-cap companies were able to finance investments and operations by borrowing, which was possible because the price of oil provided good collateral. However, increased exploration and extraction of fossil fuels as well as a slowdown in global growth forced the price of energy to adjust downward. Shale energy companies had to borrow funds continuously, accumulating high levels of debt that could be repaid if high levels of crude oil price prevailed. However, 
low oil prices currently appear to be persistent, so in the upcoming period a shakeout can be expected among firms involved in shale production: companies that are financially and operationally sound will survive, and less fortunate ones will exit the market.

This paper's theoretical model suggests that during the lengthy period when innovation and high oil price characterized the sector, the large incumbent firms lost control over their market share. But, given their size and access to finance, these firms seem likely to regain their previous market share as a result of this shakeout. This development is expected to take place over the next few years, also allowing oil price to regain momentum on the upside.

Overall, however, market shares in the energy sector are unstable, because of the unprecedented level of debt among mid- and small-cap shale oil companies. Our analysis has implications for other sectors of the economy as well. One question is whether banks and the bond market are overexposed to those vulnerable companies in the energy sector, as they were to the real estate sector before the crisis in 2008-2009. Moreover, concerns arise over whether insolvencies and shakeouts in the shale energy sector could spill over to the renewable energy sector. It will be interesting to see how energy companies, other than those involved in fossil fuel, survive in the current environment. Will the renewable energy sector experience the same fate, or will this give it an opportunity for expansion?

\section{References}

Alquist, Ron, and Justin-Damien Guénette. "A blessing in disguise: The implications of high global oil prices for the North American market." Energy Policy 64 (2014): 49-57.

Capital, Renaissance. 2014 US IPO Market Has Another Record Year. Annual Review. Renaissance, 2015.

Crooks, Ed. "US shale oil industry hit by $\$ 30$ bn outflows." 2015. http://www . ft.com/ intl/cms/s/0/5a8c9a4c-54b0-11e5-8642-453585f2cfcd.html\#axzz314Ct0Wyd.

Domanski, Dietrich, et al. Oil and debt. March. Quarterly Review. BIS, 2015. http://www. bis.org/publ/qtrpdf/r_qt1503f.htm.

Gilje, Erik, Robert Ready, and Nikolai Roussanov. "Fracking, Drilling, and Asset Pricing: Estimating the Economic Benefits of the Shale Revolution." Unpublished, 2015.

Grüne, Lars, Willi Semmler, and Marleen Stieler. "Using Nonlinear Model Predictive Control for Dynamic Decision Problems in Economics." Journal of Economic Dynamics and Control Available online 29 August (2015). http://www.sciencedirect.com/science/ article/pii/S016518891500158X.

Hamilton, James D. Oil prices, exhaustible resources, and economic growth. 17759. Working Paper. NBER, 2012. http://www .nber.org/papers/w17759.

Johansen, Soren. "Statistical analysis of cointegration vectors." Journal of Economic Dynamics and Control 12 (1988): 231-254. 
Johansen, Soren, and Katarina Juselius. "Maximum likelihood estimation and inference on cointegration - with applications to the demand for money." Oxford Bulletin of Economics and Statistics 52 (1990): 169-210.

Kato, Mika, and Willi Semmler. "Dominant firms, competition-deterring investment and antitrust policy." In Keynes, Sraffa, and the Criticism of Neoclassical Theory. Essays in Honour of Heinz D. Kurz, ed. by Neri Salvadori and Christian Gehrke. Routledge, London, 2011.

Kilian, Lutz. The Impact of the Shale Oil Revolution on U.S. Oil and Gasoline Prices. 499. Working Paper. Center for Financial Studies, 2014.

Plosser, Matthew C. Bank Heterogeneity and Capital Allocation: Evidence from "Fracking" Shocks. 693. Staff Reports. Federal Reserve Bank of New York, 2014. http://www.ny. frb.org/research/staff_reports/sr693.pdf.

Schleer, Frauke, Willi Semmler, and Julian Illner. Overleveraging in the Banking Sector: Evidence from Europe. 14-066. Discussion Paper. ZEW, 2014.

Staff, EIA. As cash flow flattens, major energy companies increase debt, sell assets. Tech. rep. U.S. Energy Information Association, 2014. http://www.eia.gov/todayinenergy/ detail.cfm?id=17311.

Staff, World Bank. Plunging oil prices. 4. Quarterly Economic Brief. World Bank Middle East and North Africa Region, 2015. http: / /www-wds . worldbank .org/external/ default/WDSContentServer/WDSP/IB/2015/01/26/000350881_20150126110740/ Rendered/PDF/938470Box385410c0Biref0January02015.pdf.

Stein, Jerome L. Stochastic Optimal Control and the U.S. Financial Debt Crisis. Springer, New York, 2012.

Sutton, James. "Putting it crudely": Oil price falls and the JPM Natural Resources portfolio. Commentary. J.P. Mrogan, 2014. http://insights . jpmorgan . co.uk/adviser / commentary-and-analysis/putting-it-crudely-oil-price-falls-and-the-jpmnatural-resources-portfolio/.

Weiss, Leonard. "Average Concentration Ratios and Industrial Performance." The Journal of Industrial Economics 11, no. 3 (1963): 237-254.

\section{Appendix}




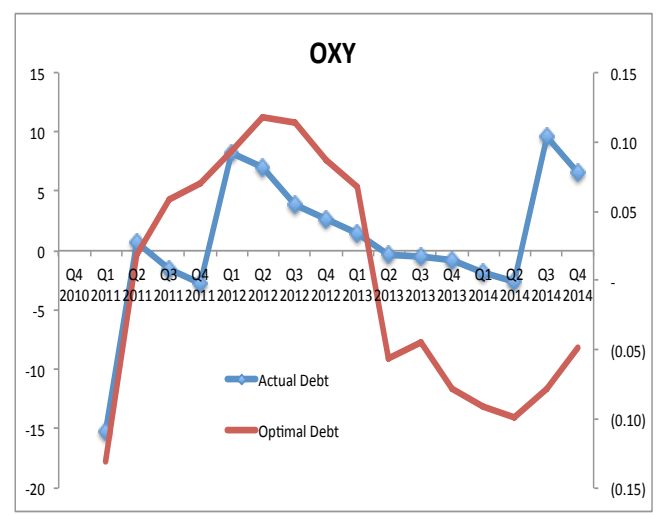

(a)

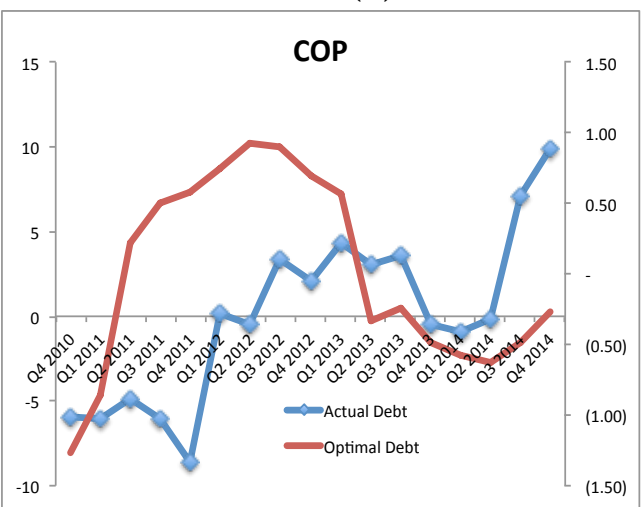

(c)

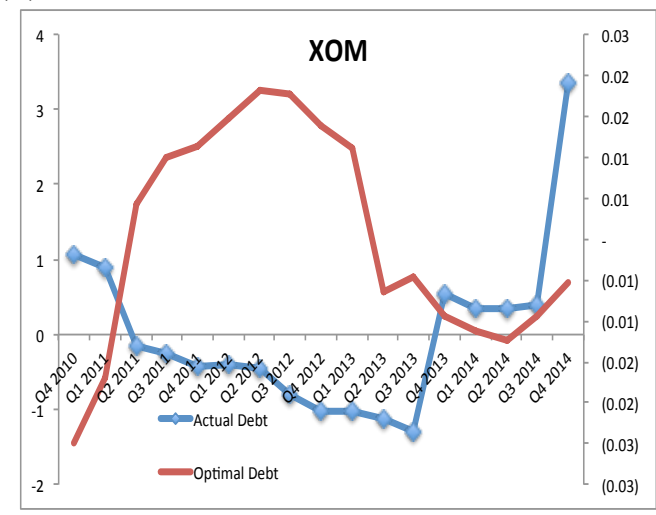

(e)

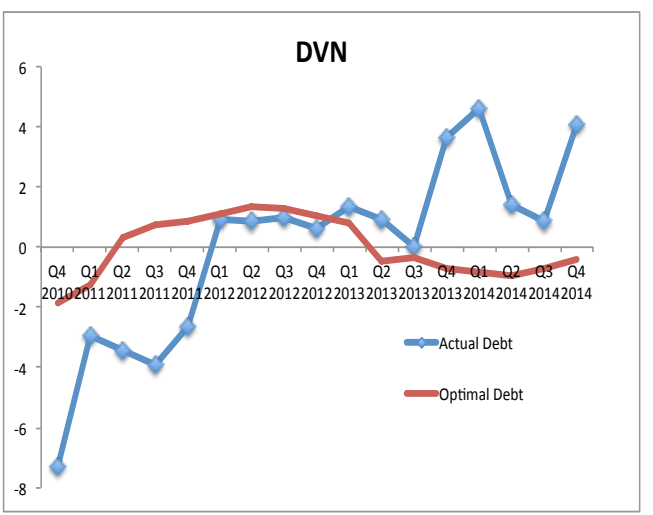

(b)

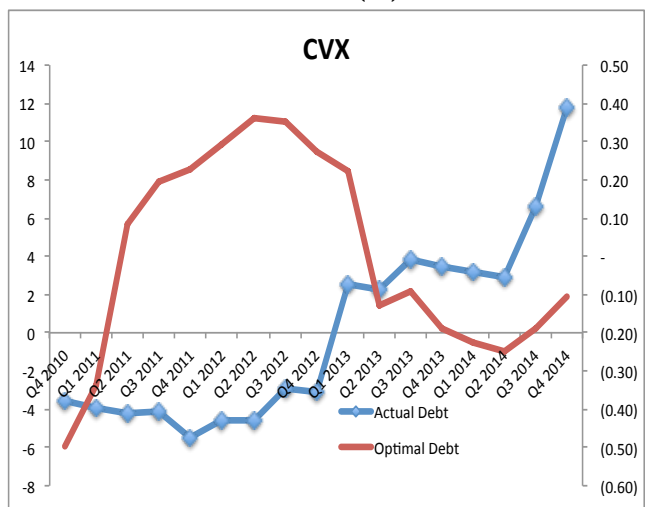

(d)

Figure A1: Actual vs. Optimal Debt, Large-Cap companies 


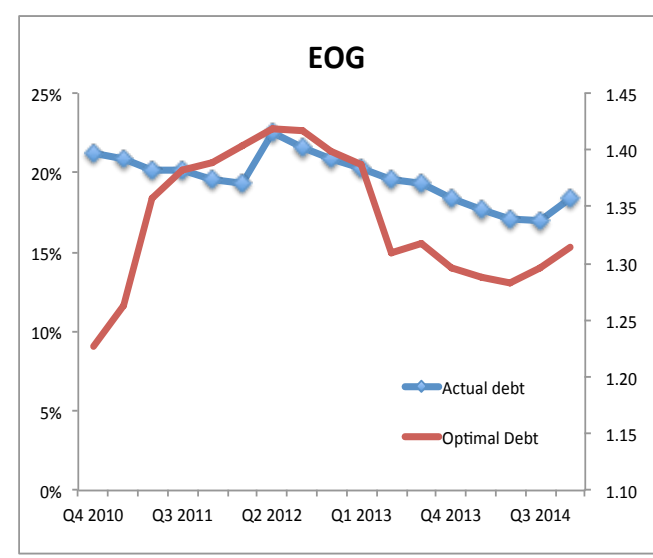

(a)

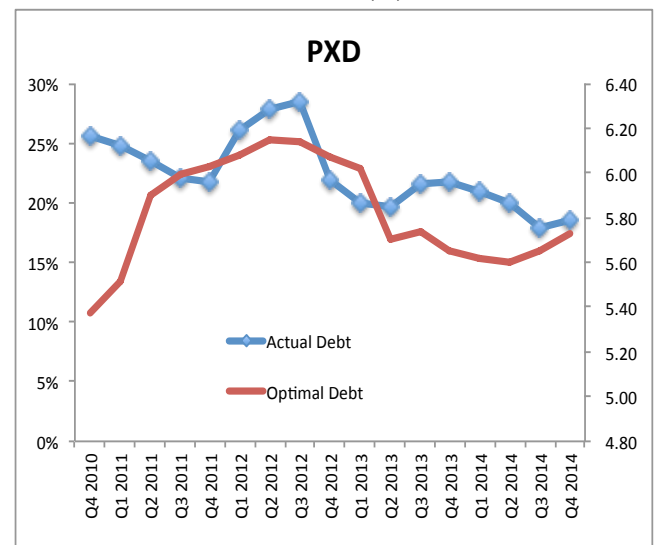

(c)

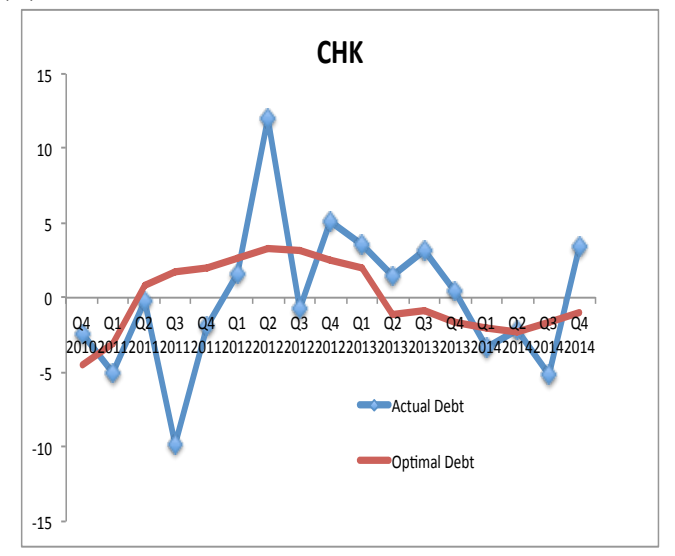

(e)

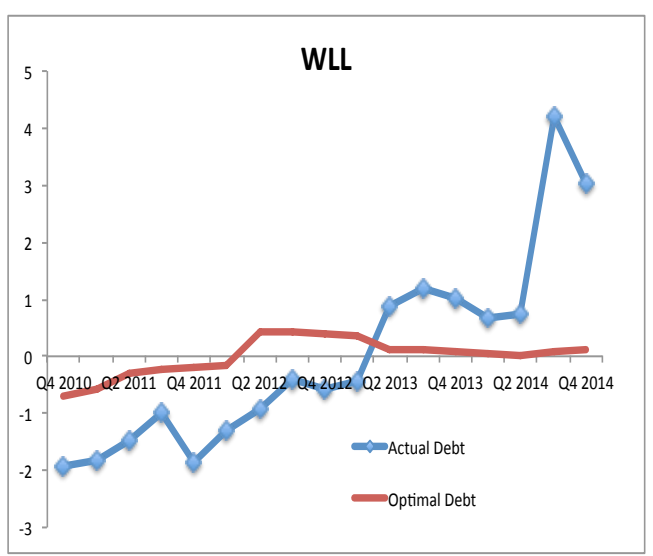

(b)

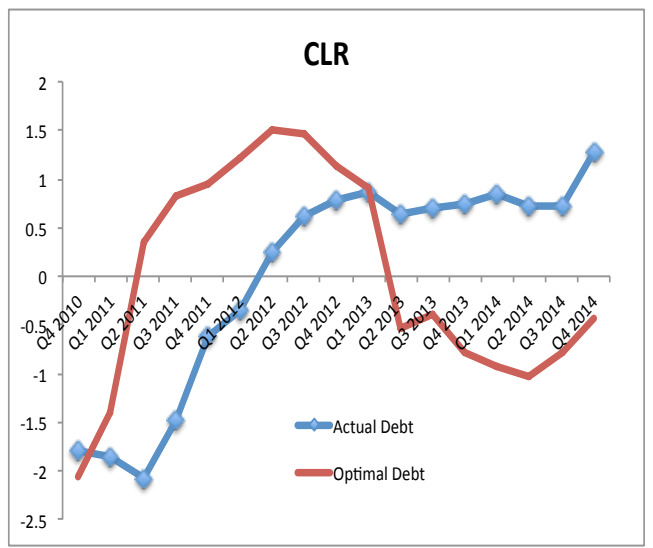

(d)

Figure A2: Actual vs. Optimal Debt, Mid-Cap companies 


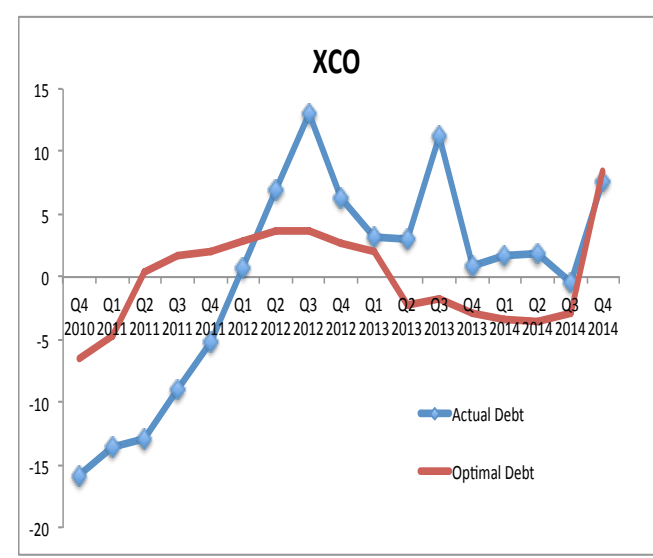

(a)

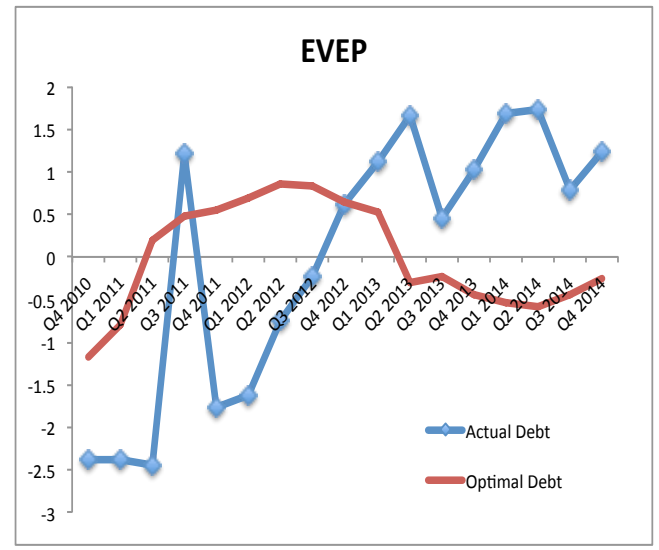

(c)

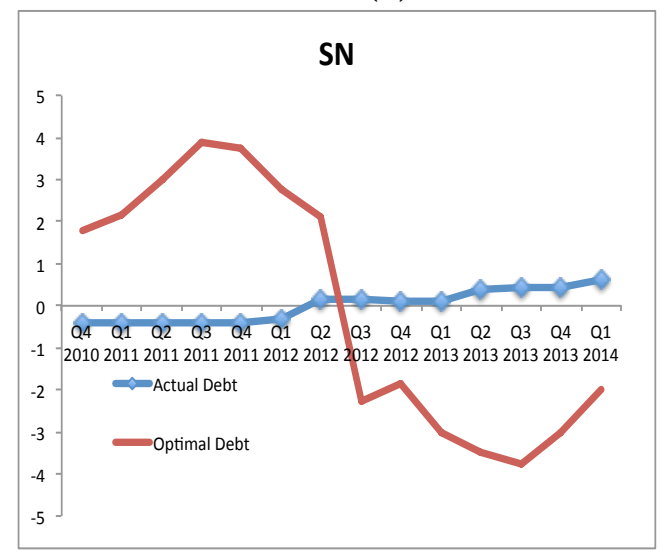

(e)

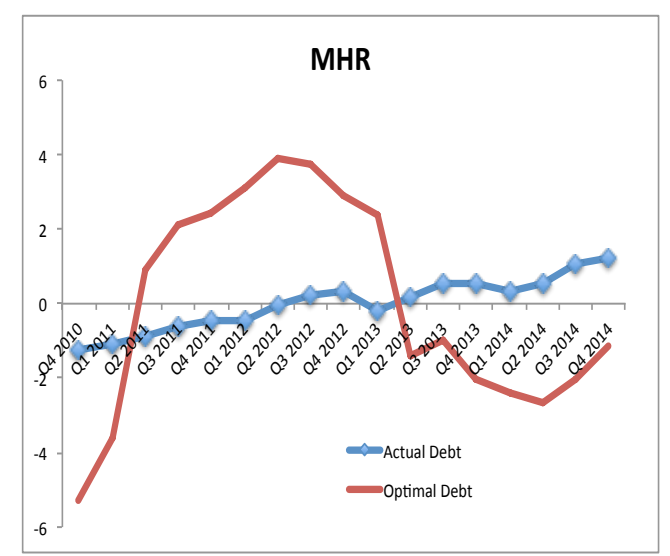

(b)

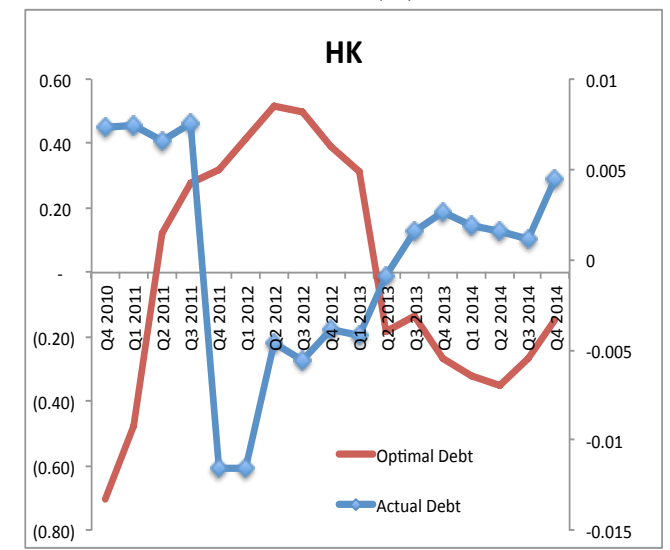

(d)

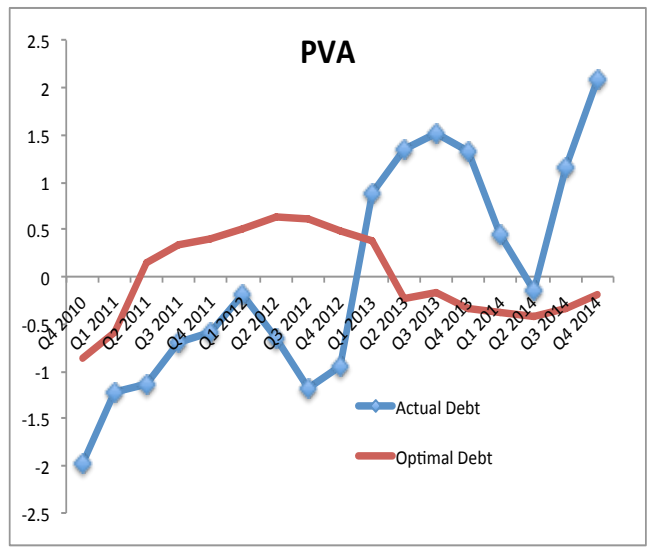

(f)

Figure A3: Actual vs. Optimal Debt, Small-Cap companies 


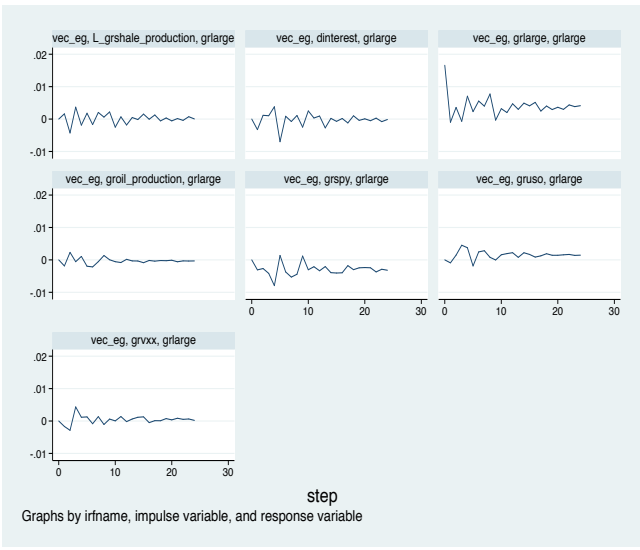

(a) Large Cap

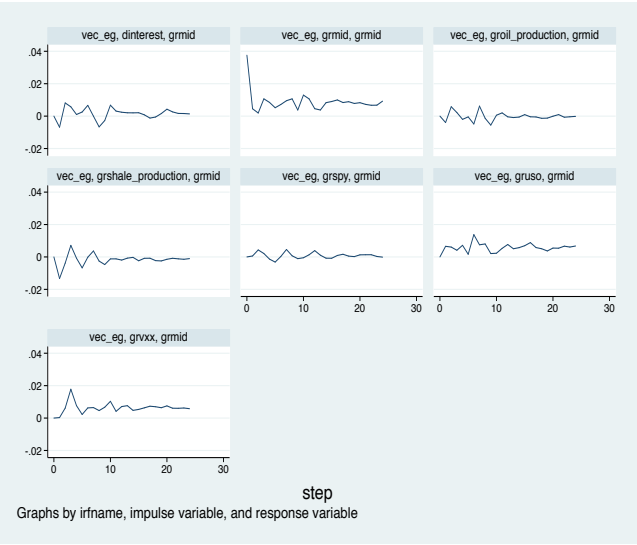

(b) Mid Cap

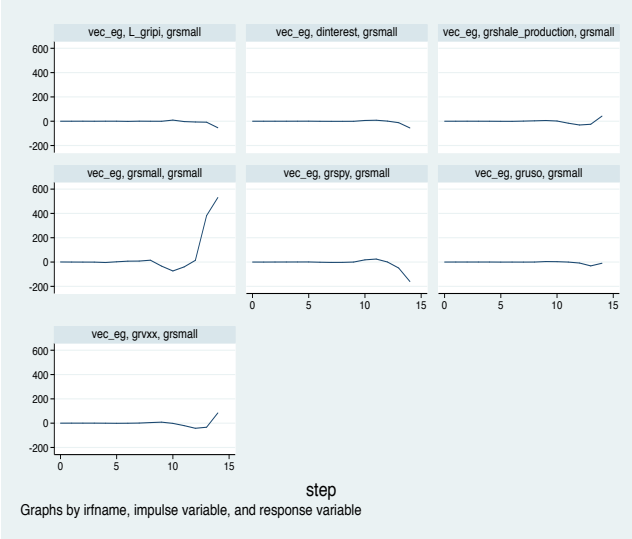

(c) Small Cap

Figure A4: Impulse response function results 